\title{
فعالة تعليم مهارة الكلام باللغة العربية أثناء الوباء كوفد 19 عبر الإنترنت
}

$$
\text { جامعة الكياهي الحاج أحمد صدادة الزهرة ، أحمد حافظ عبد الله 2، فارس ماتريديق الإسلامية الحكومية، جمبير، إندونيسيا }
$$

Shellyfzahra@gmail.com ${ }^{1}$,203206020002@iain-jember.ac.id ${ }^{2}$

0849219010@iain-jember.ac.id ${ }^{3}$

\begin{abstract}
The government has issued a policy in which schools require their students to study at home. Starting in March, the school implemented the online learning. This research aims to find out the effectiveness of online education in the era of the Covid-19 epidemic in teaching speaking skill at the Department of Arabic Language Teaching at the State Islamic University Jember. This research used the quantitative approach using the semi-experimental method. The method of data collection is the questionnaire, and the data was analyzed from the effectiveness of the test using N-Gain Score. The results of this research are It is said that online learning of speech skill is less effective, and the results of the performed calculations are $43 \%$. According to the criteria of the N-Gain Interpretation which states that if the percentage value is $40-55$, it means "less effective". Because learning the skill of speaking requires direct and interactive skills.
\end{abstract}

\section{Keywords: Arabic Language, Media, Pandemic, Speaking Skill}

$$
\begin{aligned}
& \text { التأكيد على ان انتقال الالتهاب الرئوي يمكن أن } \\
& \text { يتعدى من شخص إلى شخص آخر. حتى الآن هذا } \\
& \text { الفيروس ينتشر بسرعة لا يزال غامضا والبحث لا يزال } \\
& \text { مستمرا .أول الخبر وباء كوفيد-19 في اندونسيا في } \\
& \text { التارخ } 2 \text { مارس } 2020 \text { قاضيتان. أوضحت البيانات } \\
& \text { في التاريخ } 31 \text { مارس تأكيدا } 131 \text { } 1.528 \text { قضايا وتعداد } \\
& \text { الأومات } 136 \text { قضايا. درجة تعداد الموت في أندونسيا } \\
& \text { \%,8,9 هذه الدرجة أعلى الدرجة في جنوب شرقي } \\
& \text { آسيا. }
\end{aligned}
$$$$
\text { انتشر الوباء سريعا وتنظيما في إندونسيا ليقطع }
$$$$
\text { اذاعة هذا الوباء كوفيد-19. كتب UNESCO }
$$

2 Adityo Susilo et al., "Coronavirus Disease 2019: Tinjauan Literatur Terkini," Jurnal Penyakit Dalam Indonesia 7, no. 1 (2020): 45-67, http://www.jurnalpenyakitdalam.ui.ac.id/index.php/jpdi /article/view/415.
المقدمة

$$
\begin{aligned}
& \text { إن العالم في العصر الراهن قد مصاب بفيروس } \\
& \text { مضر. سمي هذا الفيروس باسم كوفيد-19 } \\
& \text { (Coronavirus Disease 2019). هذا الفيروس فيروس } \\
& \text { جديد (SARS-CoV-2) لم يوجد دواء لهذا الفيروس. } \\
& \text { إنتشر هذا الفيروس } 193 \text { بلاد حتى الآن.كما قال } \\
& \text { خبير بفيروس أو ريجرد سوتيجو هذا الفيروس جنس عام } \\
& \text { بالطاعون الرئوي.1 في البداية، لا يمكن تحديد البحديد انتقال } \\
& \text { هذا الفيروس بين البشر. يستمر عدد الحالات في الزيادة } \\
& \text { مع مرورة الوقت. بالإضافة إلى إصابة } 15 \text { حالة من } \\
& \text { الكوادر الطبية بأحد المرضى. في فهاية المطاف تم }
\end{aligned}
$$

\footnotetext{
${ }^{1}$ Yuliana, "Corona Virus Diseases (Covid -19); Sebuah Tinjauan Literatur," WELLNESS AND HEALTHY MAGAZINE 2, no. 1 (2020): 187-192, https://www.wellness.journalpress.id/wellness/article/v iew/21026/pdf.
} 
وبالتالي، يمكن للمدرس ضمان مشاركة الطلاب في

التعلم في نفس الوقت، حتى في أماكن مختلفة. يلعب

استخدام تكنولوجيا المعلومات دورًا مهمًا للغاية في تنفيذ

التعلم عن بعد في خضم وباء فيروس كوفيد-19،

ويمكن أن تسير عملية التعلم بشكل جيد مع وجود

تكنولوجيا المعلومات التي تطورت بسرعة في هذا الوقت

بما في ذلك التعلم الإلكتروين، فئة google و و

whatsapp

المعلومات الأخرى. الإنترنت الذي يمكنه ربط المحاضرين

والطلاب حتى تتم عملية التدريس والتعلم بشكل جيد

كما ينبغي حتى في خضم فيروس كورونا. 6 وفي الوقت

ذاته يستطيع المدرسون أن يتعايشوا مع التجديد لعملية

التعليم في العصر الراهن حيث يتطلب منهم أن يتعامل

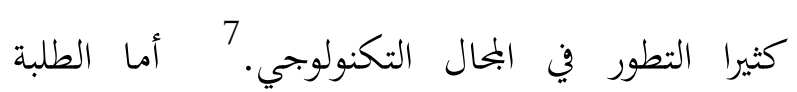

فبإمكاهم أن يتعلموا في أي مكان شاؤوا مما يؤدي إلى نمو كفاءقم حتى يتحقق المقصود من التعلم طول 8

6 Roida Pakpahan and Yuni Fitriani, “Analisa Pemafaatan Teknologi Informasi Dalam Pemeblajaran Jarak Jauh Di Tengah Pandemi Virus Corona Covid19," JISAMAR (Journal of Information System, Applied, Management, Accounting and Researh) 4, no. 2 (2020): 30-36, http://journal.stmikjayakarta.ac.id/index.php/jisamar/ar ticle/view/181.

${ }^{7}$ Siti Kulsum and Syifa Husnul, "Pemanfaatan Media Pembelajaran , Inovasi Di Masa Pandemi Covid-19," EDUKATIF : JURNAL ILMU PENDIDIKAN 3, no. 4 (2021): 2149-2158, http://journal.stmikjayakarta.ac.id/index.php/jisamar/ar ticle/view/181.

${ }^{8}$ Shivangi Dhawan, "Online Learning: A Panacea in the Time of COVID-19 Crisis," Journal of Educational Technology Systems 49, no. 1 (2020): 5-22.
وباء كوفيد-19 في التربوي حول 290,5 مليونالطلاب في كل انحاء العالم. لأن ذلك كثير من المباء

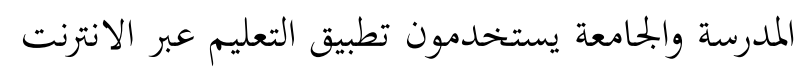

Google Classroom لمساعدة الدروس في البيت. منها Kelaspintar, Edmodo, LMS, zoom, Ruanggurug وغير ذلك من التطبيقات. ${ }^{3}$ متابعته بالتعميم رقم 15 لعام 2020 بشأن إرشادات التعليم إدارة التعلم في المنزل في حالة انتشار كوفيد 19 يرتبط أحد محتويات الرسالة الدورية بتنفيذ عملية التعليم ، والعملية التعليمية من حيث التعليم في المنزل

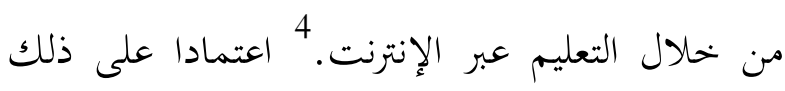

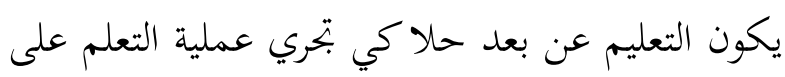
قدم وساق.

يتم تنفيذ نظام التعلم من خلال جهاز كمبيوتر

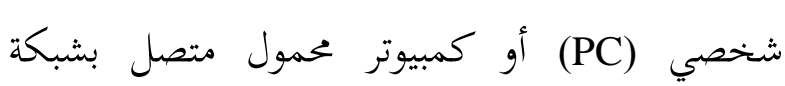
الإنترنت. يمكن للمدرسين التعلم معًا في نفس الوقت باستخدام البمموعات على وسائل التواصل الاجتماعي مثل WhatsApp (WA) أو Telegram Instagram

${ }^{3}$ Mirzon Daheri et al., "Efektifitas WhatsApp Sebagai Media Belajar Daring," Jurnal Basicedu 4, no. 4 (2020): 775-783.

${ }^{4}$ Mendikbud RI, Surat Edaran Nomor 4 Tahun 2020 Tentang Pelaksanaan Kebijakan Pendidikan Dalam Masa Darurat Penyebaran Coronavirus Disease (COVID-19), 2020 , https://www.kemdikbud.go.id/main/blog/2020/03/semendikbud-pelaksanaan-kebijakan-pendidikan-dalammasa-darurat-penyebaran-covid19.

5 Wildana Wargadinata, Iffat Maimunah, and Suci Ramadhanti, "Mediated Arabic Language Learning for Arabic Students of Higher Education in COVID-19 Situation," Izdihar: Journal of Arabic Language Teaching, Linguistics, and Literature 3, no. 1 (2020): $1-20$,

http://ejournal.umm.ac.id/index.php/izdihar/article/vie w/11862. 
يوجياكارتا" ومقالة أمر الله وأصحابه تحت عنوان

"تطبيق الوسائل الإلكترونية لتعليم اللغة العربية". ودار الكلام في هذه البحوث حول استخدام الوسائل الشبكية لعملية التعليم إلا أنه لم يكن فيها المقارنة في فعالية أنواع الوسائل الشبكية للتعليم أثناء الوباء. ويحاول هذا البحث على الإتيان بالمقارنة في فعالية الوسائل الشبكية من Zoom و Z Z Google

.Google Classroomg Meets

إذن، لا يمكن إجراء التعلم وجهًا لوجه من

جراء انتشار كوفيد 19، بينما يجب أن يستمر التعلم، لأن التعليم مهم جدًا. بعد ذلك ، لمواصلة التعلم، يتم تطبيق التعلم عبر الإنترنت. إذن، هل هذا التعلم عبر الإنترنت فعال في مهارة الكلام. يهدف هذا البحث لمعرفة فعالية التعليم عبر الإنترنت أثناء وباء كوفيد- 19 في تعليم مهارة الكالام بقسم تعليم اللغة العربية بالجامعة

$$
\begin{aligned}
& \text { الإسلامية الحكومية جمبر. } \\
& \text { منهجية البحث }
\end{aligned}
$$

يقوم هذا البحث بمنهج البحث الكمي فإنها

هي طريقة بحث تقليدية لأن الطريقة قد استخدمت لفترة طويلة بحيث تم استخدامها كأسلوب للبحث وتحليل البيانات الكمية أو الإحصائية، بهدف اختبار الفرضيات المحددة مسبقًا رآى سوجييونو. 10 تم إجراء الإسيات

البحث باستخدام المنهج شبه التجريبي حيث اعتمد الباحثون على نسبة مئوية من الإجابات التي قدمها

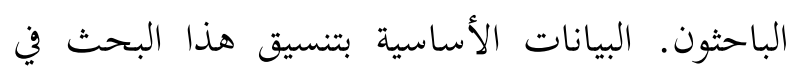

${ }^{10}$ Sugiyono, Metode Penelitian Kuantitatif, Kualitatif, Dan $R \& D$ (Bandung: Alfabeta, 2012). hal. 89
يختلف تدريس اللغات الأجنبية، وخحاصة

العربية، عن تدريس المواد الأخرى. إتقان الكلام هو أحد أنواع القدرة اللغوية التي يجب تحقيقها في تدريس اللغة. مهارة الكلام بلغة معينة له جانب من جوانب الاتصال ثنائي الاتجاه، أي بين المتكلم والمستمع بينهما شكل متبادل. وبالتالي، يجب أن تستند ممارسة التكلم باللغة العربية إلى القدرة على الاستماع والقدرة على التكلم والتمكن (النسبي) من المفردات والتعبيرات التي تسمح للطلاب بالتعبير عن نواياهم/أفكارهم. دور مهارة الكلام فهو مهم جدا بهاذه الأحوال. من له كفاءة مهارة الكلام عند التعلم أو خارج التعلم فيستطيع ان يتبحر علوما أو معرفة في انحاء العلم. إن الكلام هو مهارة انتاجية من المتعلم القدرة على استخدام الأصوات بدقة. والتمكن من الصيغ النحوية وترتيب الكلمات التي تساعده على التعبير عما يريد ان يقوله في موافق الحديث. وقد سبقت عديد من الدراسات حول تعليم مهارة الكلام عبر الإنترنت أثناء الوباء. منها المقالة بقلم ناناع قاسم وامام ترمذي ونوفي مريم وعبد الهادى تحت الموضوع "تعلم اللغة العربية عبر الإنترنت، مشاكل، الحلول والأمل" والمقالة بقلم جاغاد أدتيا وهرو نورغيينشة بالموضوع "فعالية التعلم عبر الإنترنت في عصر وباء كوفيد- 19 للطلاب جامعة PGRI

${ }^{9}$ Kamil Mahmud Thuaimah, Rusydi Ahmad; Naqah, $A l$ Kitab Al Asasiy Li Ta'lim Al Lughah Al Arabiyyah Li an Nathiqina Bi Lughat Ukhra (I'daduhu Wa Tahliluhu Wa Taqwimuhu) (Makkah: جامعة أم القرى, 1983). hal. 63 
1 التعلم.

2) يجب أن يكون نظام التعلم شخصيًا بحيث لا لا يكون مستخدمو النظام معتمدين على بعضهم البعض.

يجب أن يكون النظام سريعًا في عملية البحث عن

المواد أو الإجابة على الأسئلة من نتائج تصميم

$$
\text { النظام الجاري تطويره. }
$$

فيما يلي بعض تطبيقات التعلم التي يشيع

استخدامها من قبل المعلمين والطلاب في التعلم عبر

الإنترنت بقسم تعليم اللغة العربية بالجامعة الإسلامية

$$
\text { الحكومية جمبر : }
$$

LMS $(1$

هو برنامج يقوم بأتمتة إدارة التدريب.

يسجل LMS المستخدمين، ويتتبع الدورات في كتالوج،

ويسجل البيانات من الطلاب. ويوفر أيضًا إدارة

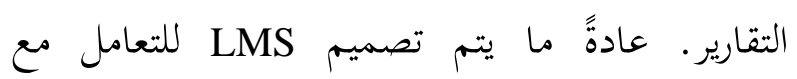

الدورات التدريبية بواسطة العديد من الناشرين والموفرين.

عادة لا تشمل قدرات التأليف وحدها بدلا من ذلك،

فإنه يركز أكثر على ترتيب الدورات التي قدمتها مصادر

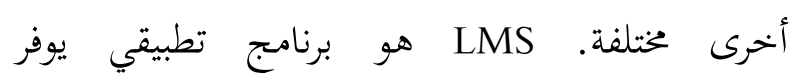

التسهيلات الإدارية والتوثيق والتتبع وتقارير الدورات

والفصول والتدريب الذي تم إجراؤه. 13 عند استخدام

\&redir_esc=y\#v=onepage \&q=Konsep Pembelajaran Daring Berbasis Pendekatan Ilmiah\&.

${ }^{13}$ Atik Ariesta, "Kajian Learning Management System (LMS) Dengan Qualitative Weight and Sunm ( QWS ): Studi Kasus D3 Unggulan Universitas Budi Luhur," JURNAL BIT 9, no. 2 (2012): 10-17, https://journal.budiluhur.ac.id/index.php/bit/article/vie w/504/436.
شكل قائمة نتائج الإختبارات التي أجريت على الطلاب في الفصل الواحد. في حين أن مصادر البيانات

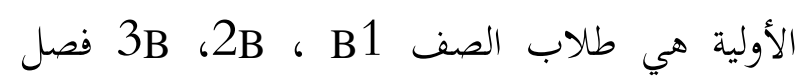
دراسي 8.

تحتاج الأداة الجيدة عمومًا إلى متطلبين مهمين، وهما الصلاحية والموثوقية. يتم ذلك بهدف أن تكون الأسئلة المستخدمة صحيحة. يهلدف اختبار الصلاحية إلى ضمان أن نتائج القياس متوافقة مع ما يتم قياسه. 11 يمكن حساب الصلاحية باستخدام صيغة المنتج 16.0SPSS لحظات. ستتم مقارنة نتائج حسابات بقيمة 5\% المستخدمة. يتم استخدام نتائج N-gain كمقارنة بين ما قبل التعلم وبعده. صيغة تحديد N-gain بدرجة مثالية 100.

تحليلها ومناقشها أ. التعليم عبر الإنترنت

مبدأ التعلم عبر الإنتزنت هو تنفيذ التعلم الهادف، أي عملية التعلم الموجهة نخو التفاعل وأنشطة التعلم التعليمية التي لا تركز على إعطاء مهام التعلم

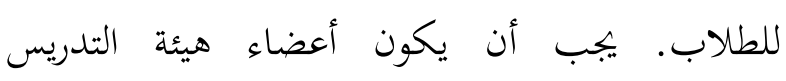
والتدريس متصلين في عملية التعلم عبر الإنترنت. وبحسب منور، يجب أن يشير تصميم نظام التعلم عبر الإنترنت إلى ثلاثة مبادئ يجب الوفاء بها: 12

${ }^{11}$ T. N. Reksoatmodjo, Statistika Untuk Psikologi Dan Pendidikan (Bandung: PT Refika Aditama, 2007). hal. 40

${ }^{12}$ Albert Efendi Pohan, Konsep Pembelajaran Daring Berbasis Pendekatan Ilmiah (CV. Sarnu Untung, 2020),

https://books.google.co.id/books?hl=id\&lr=\&id=s9bsD wAAQBAJ\&oi=fnd\&pg=PR3\&dq=Konsep+Pembelaja ran+Daring+Berbasis+Pendekatan+Ilmiah\&ots=CsVW Q6FmPm\&sig=WlOe1VvO8w0mjoK7KsNBxo8gChc 
أحد التطبيقات التي توفر تسهيلات التفاعل

وجهًا لوجه للمعلمين والطلاب افتراضيًا عبر مؤتمر

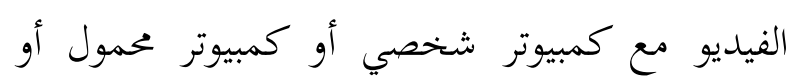

هاتف ذكي هو Zoom Cloud Meeting. هذا

التطبيق هو تطبيق يتم استخدامه كوسيلة للاتصال عن

بعد من خلال الجمع بين مؤتمرات الفيديو والدردشة

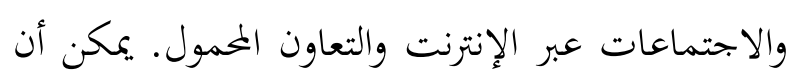

يستوعب استخدام الاجتماعات في هذا التطبيق

1000 مشارك معًا في اجتماع واحد تقريبًا. يمكن

تنزيل هذا التطبيق بحانًا، ولكن لا يزال يعمل، وتشمل الميزات المكالمات الهاتفية والندوات والعروض التقديمية

$$
\text { والعديد من الميزات الأخرى. } 15
$$

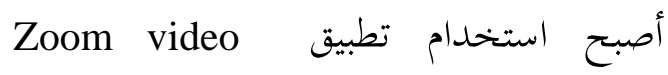

شائع الاستخدام الآن. أحد أسباب Conference ذلك هو انتشار فيروس كوفيد - 19، منذ بداية عام 2020. ونتيجة لانتشار الفيروس، يجب إعادة الناس وليس إلى منازهم لكسر سلسلة انتشار الفيروس.

بصرف النظر عن مسألة الحصص التي يشعرون

أهفا مرهقة، فإن التعلم عبر الإنترنت من خلال Zoom

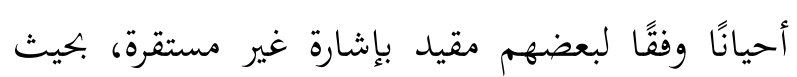
يكون Zoom الذي يصلون إليه متقطعًا في بعض الأحيان. يرجع هذا العامل إلى نطاق الموقع لكل موفر يستخدمه الطلاب، مع مواقع مختلفة حيث يمكنهم

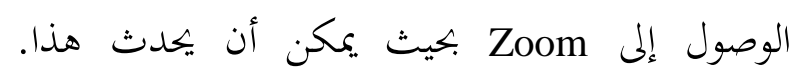

15 Junita Monica and Dini Fitriawati, "Efektivitas Penggunaan Aplikasi Zoom Sebagai Media Pembelajaran Online Pada Mahasiswa Saat Pandemi Covid-19 As An Online Learning Medium For Students During The Covid-19 Pandemic," Jurnal Communio: Jurnal Jurusan Ilmu Komunikasi 9, no. 2 (2020): 1630-1640, http://ejurnal.undana.ac.id/JIKOM/article/view/2416.
عبر الإنترنت، يجب أن يحتوي LMS الوظائف التالية:14 1. تحميل ومشاركة المواد: يوفر LMS خدمات لتبسيط عملية نشر مواد عملية التعلم. سيقوم المدرب بتحميل المواد التعليمية وفقًا للمنهج الذي تم إعداده، والتي يمكن أن تكون في شكل ملاحظات مادية ومقالات ومسابقات وتقييمات وغيرها. 2. المنتدى والرسم البياني : المنتديات والمحادثات عبارة عن تواصل بين المدرسين/المحاضرين والطلاب، إما

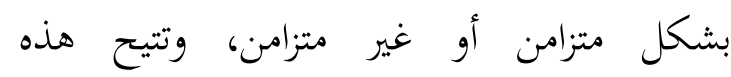

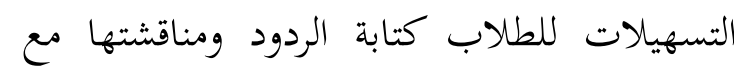
الأصدقاء الآخرين.

3. الإختبارات والإستطلاعات: يمكن أن توفر الإختبارات والإستطلاعات عبر الإنترنت درجات فورية للطلاب. هذه أداة جيدة جدًا لاستخدامها للحصول على تعليقات مباشرة من الطلاب وفقًا لقدراتم واستيعابهم. 4. جمع ومراجعة الواجب: النتائج التي يتم الحصول عليها من تقييم/مراقبة بناح التعلم، أي إعطاء الدرجات أو الدرجات للطلاب يتم إجراؤها تلقائيًا

$$
\text { 5. تسجيل الدبر الإنترنت. }
$$$$
\text { من الطلاب وتسجيلها تلقائيًا. }
$$

ZOOM (2

14 Agus Darmawan, "PEMILIHAN SISTEM LEARNING MANAGEMENT SYSTEM ( LMS ) METODE AHP MENGGUNAKAN CRITERIUM DECISION PLUS 3 . 0," Faktor Exacta 7, no. 3 (2014): 260-270, Elearning, LSM, Analytic Hierarchy Process, Criterium Decision Plus 3.0\%0AAbstract. 
تنص Google على أن Google Classroom

هي خدمة بوابة فعالة تسهل على المعلمين إدارة مواد التدريس والواجبات. بالإضافة إلى تسهيل الأمر على

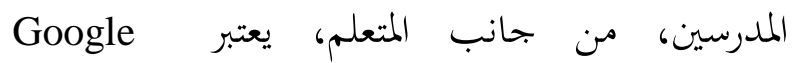
Classroom

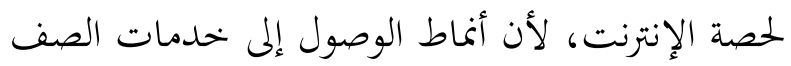
عبر الإنترنت على النظام الأساسي يتم إنشاؤها مثل

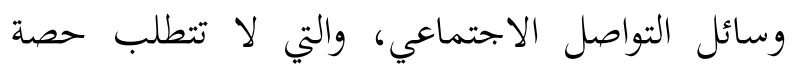
زائدة للوصول إليها.

يهدف Google Classroom إلى تسهيل كتابة الطلاب وتعيين مهام غير ورقية للطلاب. الواجبات في Google Classroom في تئل مستندات أو مقاطع فيديو ومناقشات. بالإضافة إلى ذلك، يمكنك أيضًا إجراء اختبارات عبر الإنترنت باستخدام تنسيق Google Form مع أنواع مختلفة من الأسئلة. لتسجيل الدخول إلى Google Classroom، يبحث مستخدمو حساب Gmail فقط عن قائمة Google Classroom Gmail Google Meet (4

https://ejournal.stkippacitan.ac.id/index.php/jpp/article/ view/226.

18 Naserly, "IMPLEMENTASI ZOOM, GOOGLE CLASSROOM, DAN WHATSAPP GROUP DALAM MENDUKUNG PEMBELAJARAN DARING (ONLINE) PADA MATA KULIAH BAHASA INGGRIS LANJUT (Studi Kasus Pada 2 Kelas Semester 2, Jurusan Administrasi Bisnis, Fakultas Ekonomi Dan Bisnis, Universitas Bina Sa."

19 Ahmad Muslik, "Google Classroom Sebagai Alternatif Digitalisasi Pembelajaran Matematika Di Era Revolusi Industri 4.0," Andragogi: Jurnal Diklat Teknis Pendidikan dan Keagamaan 7, no. 2 (2019): 246-255, https://pusdiklattekniskemenag.ejournal.id/andragogi/issue/view/8.
بالنسبة لهذا العامل، يمكن اعتباره الجحانب الأكثر أهمية، لأنه إذا كانت المحاضرات من خحلال Zoom لا تزال مفروضة، فلا يمكن لجميع الطلاب الاستفادة من المواد المقدمة، لأن بعضها لا يزال مقيدًا بظروف الإشارة السيئة. 16

Google Classroom (3 يحتوي Google Classroom على العديد من الميزات التي يمكن استخدامها في عملية التعلم، بما في ذلك الصفحة الرئيسية التي يمكنها عرض مهام الطلاب وترتيب الفصل وتخزين البيانات على Google Drive، ويمكن الوصول إليها عبر الهاتف الذكي، بالإضافة إلى

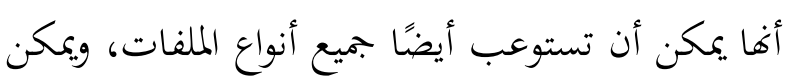
إضافة صورة للملف الشخصي. بالإضافة إلى ذلك، هناك أيضًا ميزات أخرى يمكن أن يستخدمها المحاضرون في تطوير المواد التعليمية، مثل إعادة استخدام المنشورات، وإنشاء الأسئلة، وإنشاء المهام، وإنشاء

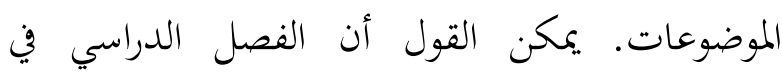
Google التعلم بالاستفسار لأن Google Classroom يمكن أن ونس يشرك قدرات الطلاب إلى أقصى حد في البحث والفهم والتحقيق والتحليل وصياغة نتائج التعلم. 17

16 Mursyid Kasmir Naserly, "IMPLEMENTASI ZOOM, GOOGLE CLASSROOM, DAN WHATSAPP GROUP DALAM MENDUKUNG PEMBELAJARAN DARING (ONLINE) PADA MATA KULIAH BAHASA INGGRIS LANJUT (Studi Kasus Pada 2 Kelas Semester 2, Jurusan Administrasi Bisnis, Fakultas Ekonomi Dan Bisnis, Universitas Bina Sa," Jurnal AKSARA PUBLIC 4, no. 2 (2020): 155-165, http://aksarapublic.com/index.php/home/article/view/4 17.

17 Abd. Ghofur, "USING GOOGLE CLASSROOM ON INQUIRY BASED LEARNING TO IMPROVE STUDENTS ' LEARNING PARTICIPATION," Jurnal Penelitian Pendidikan 10, no. 2 (2018): 15031509 , 
Google Meet

نتائج حساب اختبار N-Gain بمساعدة

احتياجات الاتصال في أي مكان وزمان مع العديد من برنامج 22.0SPSS، القيمة في شكل نسبة مئوية

(\%) موجودة في الملحق 5 جدول N-Gain Score

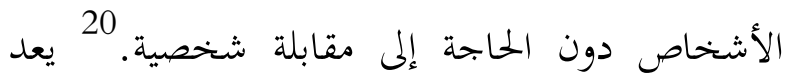
التعلم عن بعد أو التعلم الإلكتروني حاجة هائلة اليوم، Test Output

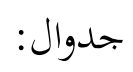

N-Gain Score نتائج حساب اختبار نيجة اختبار N-Gain

\begin{tabular}{|c|c|c|c|c|}
\hline & \multicolumn{2}{|c|}{ المحموعة } & Statistic & $\begin{array}{l}\text { Std. } \\
\text { Error }\end{array}$ \\
\hline \multirow{14}{*}{$\begin{array}{l}\text { N Gain } \\
\text { Prosen }\end{array}$} & Mean & & 43.4128 & 2.43466 \\
\hline & $95 \%$ & Lower & 38.5490 & \\
\hline & Confidence & Bound & & \\
\hline & $\begin{array}{l}\text { Interval for } \\
\text { Mean }\end{array}$ & $\begin{array}{l}\text { Upper } \\
\text { Bound }\end{array}$ & 48.2766 & \\
\hline & $5 \%$ Trimme & Mean & 43.4500 & \\
\hline & Median & & 45.4545 & \\
\hline & Variance & & 385.293 & \\
\hline & Std. Deviati & & 19.62889 & \\
\hline & Minimum & & 3.64 & \\
\hline & Maximum & & 82.19 & \\
\hline & Range & & 78.56 & \\
\hline & Interquartile & Range & 33.49 & \\
\hline & Skewness & & -.069 & 297 \\
\hline & Kurtosis & & -.933 & .586 \\
\hline
\end{tabular}

N-Gain Score فإنه يُظهر أن متوسط قيمة Score

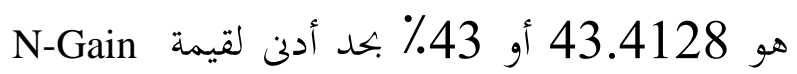

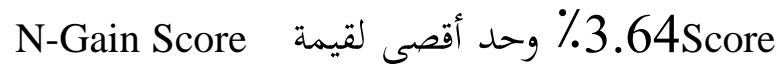
82.19 \% لتفسير فعالية N-Gain: N-Gain تفسير فعالية

\begin{tabular}{|c|c|c|}
\hline رقم & (3) & (1) \\
\hline 4 & 3 & 1 \\
\hline
\end{tabular}

20 Bambang Warsita, Pendidikan Jarak Jauh: Perancangan, Pengembangan, Implementasi, Dan Evaluasi Diklat. (Bandung: Remaja Rosdakarya, 2011). hal. 67

21 Achmad Fatkhurrozi et al., "EFEKTIVITAS PEMBELAJARAN DARING MENGGUNAKAN GOOGLE MEET DAN WHATSAPP GROUP UNTUK MENINGKATKAN HASIL BELAJAR MATEMATIKA SELAMA," MODELING: Jurnal Program Studi PGMI 8, no. 1 (2021): 28-42, http://jurnal.stitnualhikmah.ac.id/index.php/modeling/a rticle/view/717. 
فيما يلي تفسير نتائج اختبار N-Gain Score وفقًا لكل مستجيب:

\begin{tabular}{|c|c|c|c|c|c|}
\hline \multicolumn{6}{|c|}{ N-Gain تفسير فعالية } \\
\hline & & $\begin{array}{l}\text { Freque } \\
\text { ncy }\end{array}$ & $\begin{array}{c}\text { Perce } \\
\text { nt }\end{array}$ & $\begin{array}{c}\text { Valid } \\
\text { Perce } \\
\text { nt }\end{array}$ & $\begin{array}{c}\text { Cumulati } \\
\text { ve } \\
\text { Percent }\end{array}$ \\
\hline \multirow[t]{5}{*}{ Valid } & $\begin{array}{l}\text { Tidak } \\
\text { Efektif }\end{array}$ & 26 & 36.1 & 40.0 & 40.0 \\
\hline & $\begin{array}{l}\text { Kurang } \\
\text { Efektif }\end{array}$ & 19 & 26.4 & 29.2 & 69.2 \\
\hline & $\begin{array}{l}\text { Cukup } \\
\text { Efektif }\end{array}$ & 17 & 23.6 & 26.2 & 95.4 \\
\hline & Efektif & 3 & 4.2 & 4.6 & 100.0 \\
\hline & Total & 65 & 90.3 & 100.0 & \\
\hline $\begin{array}{l}\text { Missi } \\
\text { ng }\end{array}$ & System & 7 & 9.7 & & \\
\hline Total & & 72 & 100.0 & & \\
\hline
\end{tabular}

بناءً على البيانات الواردة أعلاه، يُقال إن

التعلم عبر الإنترنت أقل فعالية. بسبب العديد من

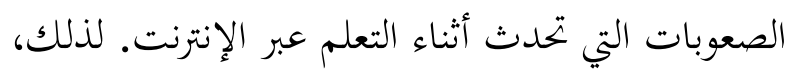
أجرى الباحثون أيضًا مقابلات مع العديد من الطلاب حول فعالية التعلم عبر الإنترنت على مهارة كلام.

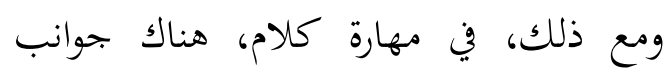
يجتاج الطلاب إلى إتقاها عند التحدث باللغة العربية. وهي القواعد والطلاقة وأسلوب اللغة. لذلك أجرى الباحثون مقابلات لمعرفة مدى فاعلية مهارة كلام في

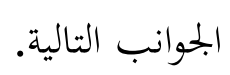
بعد إجراء العديد من المقابلات مع الطلاب، لماذا أقل فعالية التعلم عبر الإنترنت في مهارة كلام، وفقًا إيلا، يتطلب تعلم الكالام تعلمًا عمليًا حقيقيًا. لأن في تعلم اللغة ما نحتاجه هو مهارة. مقدار التفاعل بين الطلاب والمحاضرين والطلاب مع الطلاب الآخرين

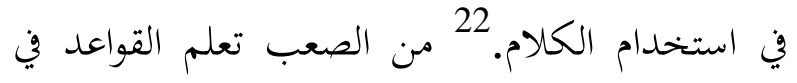
التعلم عبر الإنترنت، ناهيك عن أن المحاضرين الذين

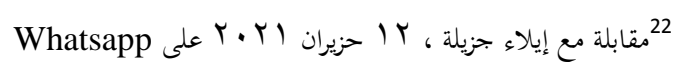

\begin{tabular}{|c|c|c|}
\hline الحصيلة & نسبة مئوية (\%) & رقم \\
\hline غير فعال & $40<$ & 1 \\
\hline أقل فعالية & $40-55$ & 2 \\
\hline فعالة بما فيه الكفاية & $56-75$ & 3 \\
\hline فعال & $76>$ & 4 \\
\hline
\end{tabular}

استنادًا إلى الجدول 4.12، جدول التفسير لفعالية N-Gain، والتي تبلغ 43\%، لذلك يمكن استنتاج أن التعلم عبر الإنترنت نهو مهارة كلام أقل فعالية. فيما يلي استجابة الطلبة نحو أقل الوسائل فعالية عند تعليم مهارة الكلام. صورة 1. بيان لاستجابة الطلبة نخو الوسائل أقلها فعالية

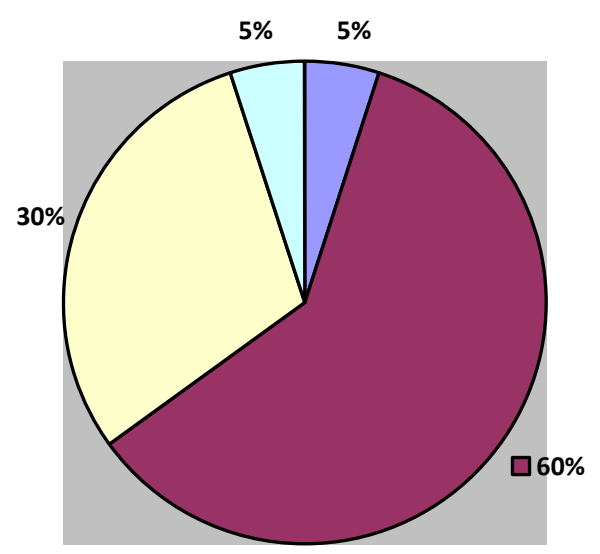

\begin{tabular}{|ll|}
\hline$\square$ LMS & $\square$ Zoom \\
$\square$ Google Meet & $\square$ Google Classroom \\
\hline
\end{tabular}

اعتمادا على البيانات أعلاه علم أن معظم الطلبة اختاروا Zoom على غيرها من الوسائل لتعليم مهارة الكالام لأهما أكثر الوسائل سهولة وبلغت النسبة \% 600gle من الطلبة ويليها في سهولة استعمالها حeets وصارت Google Classroom و LMS المركز الثالث من الوسائل الأقل فعالية لتعليم مهارة الكلام حيث بلغت نسبة من اختار هذه الوسيلة 5\% 
يتم بدون إشراف، العدو الأكبر في تنفيذ هذه الممارسة هو الذات وأيضًا التعلم سهل الفهم عند وجهاً لوجه.

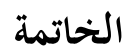

بناءً على الإختبارات التي تم إجراؤها باستخدام

درجة N-Gain، ذكر أن المعدل الذي تم الحصول عليه

في الاختبار القبلي واللاحق كان 43\%. يمكن أن نرى

من هناك، وفقًا لتفسير N-Gain، أن القيمة 55 40 تم الإعلان عنها بأها أقل فعالية. لذلك، يعتبر تعلم مهارات التحدث عبر الإنترنت أقل فعالية.

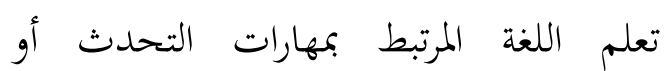

الممارسة. في التعلم عبر الإنترنت، يواجه الطلاب العديد

من الصعوبات مثل صعوبات الإشارة، والجحداول الزمنية التي تتغير أحيانًا، وقلة التفاعل بين الطلاب والمحاضرين والطلاب والطلاب لزيادة مهارة كلامهم. ولكن محا لا شك فيه أن التعلم عبر الإنترنت مرن للغاية. ومع ذلك،

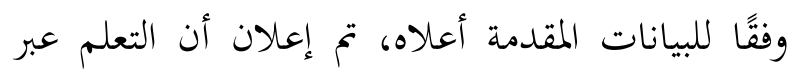

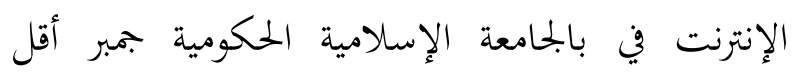

$$
\text { فعالية. }
$$

Ariesta, Atik. "Kajian Learning Management System (LMS) Dengan Qualitative Weight and Sunm ( QWS ): Studi Kasus D3 Unggulan Universitas Budi Luhur." JURNAL BIT 9, no. 2 (2012): 10-17. https://journal.budiluhur.ac.id/index.php/ bit/article/view/504/436.

Daheri, Mirzon, Juliana Juliana, Deriwanto Deriwanto, and Ahmad Dibul Amda. "Efektifitas WhatsApp Sebagai Media Belajar Daring." Jurnal Basicedu 4, no. 4 (2020)

Darmawan, Agus. "PEMILIHAN SISTEM LEARNING MANAGEMENT SYSTEM ( LMS ) METODE AHP MENGGUNAKAN CRITERIUM DECISION PLUS 3 . 0." Faktor Exacta 7, no. 3 (2014): 260-270. Elearning,
يشرحون في بعض الأحيان ليسوا واضحين، خاصة عندما تكون الإشارة سيئة. حتى في التحدث بطلاقة أمر صعب للغاية، وفقًا لستي، فإن التحدث باللغة العربية بطلاقة يتطلب التعود وبيئة ناطقة باللغة العربية. مثل التحدث في الفصل مع الأصدقاء والعروض التقديمية التفاعلية للفصل. ومثل هذا التعود والبيئة مطلوبان في مهرة الكلام. بينما يميل الطلاب إلى التعلم عبر الإنترنت إلى لى

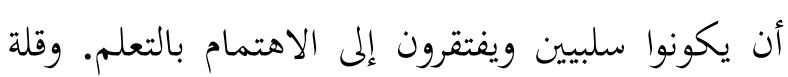
استجابة الطلاب أثناء التعلم. 23

يكون الطلاب أقل استجابة عند التعلم، وفي بعض الأحيان يُتركون أيضًا للنوم، وهم موجودون فقط في التطبيق. ناهيك عن أن الهاتف الممول مليء بالتخزين. لا يحصل الطلاب أيضًا على بيئة لغة عربية تدعم التعلم عبر الإنترنت.

التعلم مباشرة فعال للغاية، لا سيما في مهارة الكلام. لأن المدرسين يمكنهم رؤية النشاط بشكل مباشر ومدى استجابة الطلاب والتحكم بحرية أكبر في التعلم في الفصل. بينما في التعلم عبر الإنترنت، هناك

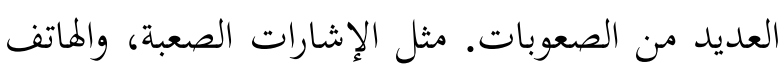
المحمول البطيء، وعدم وجود حزمة، وأقل تفاعلية في

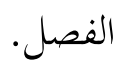

من نتائج المقابلات أعلاه، يمكننا أن نفهم أن بيئة اللغة العربية مهمة جدًا في مساعدة الطلاب على تحسين مهارة كامهم. ودعم في تعلم اللغة العربية.

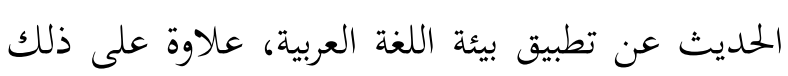

IAIN مقابلة مع موقع ستي نور هدايتي، 15 حزيران (يونيو) 2021 في Jember 
(2020): 1630-1640. http://ejurnal.undana.ac.id/JIKOM/article /view/2416.

Muslik, Ahmad. “Google Classroom Sebagai Alternatif Digitalisasi Pembelajaran Matematika Di Era Revolusi Industri 4.0." Andragogi: Jurnal Diklat Teknis Pendidikan dan Keagamaan 7, no. 2 (2019): 246-255. https://pusdiklattekniskemenag.ejournal.id/andragogi/issue/view/8.

Naserly, Mursyid Kasmir. "IMPLEMENTASI ZOOM, GOOGLE CLASSROOM, DAN WHATSAPP GROUP DALAM MENDUKUNG PEMBELAJARAN DARING (ONLINE) PADA MATA KULIAH BAHASA INGGRIS LANJUT (Studi Kasus Pada 2 Kelas Semester 2, Jurusan Administrasi Bisnis, Fakultas Ekonomi Dan Bisnis, Universitas Bina Sa." Jurnal AKSARA PUBLIC 4, no. 2 (2020): 155-165. http://aksarapublic.com/index.php/home/ article/view/417.

Pakpahan, Roida, and Yuni Fitriani. "Analisa Pemafaatan Teknologi Informasi Dalam Pemeblajaran Jarak Jauh Di Tengah Pandemi Virus Corona Covid-19." JISAMAR (Journal of Information System, Applied, Management, Accounting and Researh) 4, no. 2 (2020): 30-36. http://journal.stmikjayakarta.ac.id/index. php/jisamar/article/view/181.

Pohan, Albert Efendi. Konsep Pembelajaran Daring Berbasis Pendekatan Ilmiah. CV. Sarnu Untung, 2020. https://books.google.co.id/books?hl=id\& $\mathrm{lr}=\& \mathrm{id}=\mathrm{s} 9 \mathrm{bsDwAAQBAJ} \& \mathrm{oi}=\mathrm{fnd} \& \mathrm{pg}=$ PR3\&dq=Konsep+Pembelajaran+Daring + Berbasis+Pendekatan+Ilmiah\&ots $=\mathrm{Cs}$ VWQ6FmPm\&sig=WlOe1VvO8w0mjo K7KsNBxo8gChc\&redir_esc $=y \# v=$ onep age \&q=Konsep Pembelajaran Daring Berbasis Pendekatan Ilmiah\&.

Reksoatmodjo, T. N. Statistika Untuk Psikologi Dan Pendidikan. Bandung: PT Refika Aditama, 2007.

Sugiyono. Metode Penelitian Kuantitatif, Kualitatif, Dan $R \& D$. Bandung: Alfabeta, 2012.
LSM, Analytic Hierarchy Process, Criterium Decision Plus 3.0\%0AAbstract.

Dhawan, Shivangi. "Online Learning: A Panacea in the Time of COVID-19 Crisis." Journal of Educational Technology Systems 49, no. 1 (2020)

Fatkhurrozi, Achmad, Inqidloatul Amaniyah, Ika Rahmawati, and Siti Lailiyah. "EFEKTIVITAS PEMBELAJARAN DARING MENGGUNAKAN GOOGLE MEET DAN WHATSAPP GROUP UNTUK MENINGKATKAN HASIL BELAJAR MATEMATIKA SELAMA." MODELING: Jurnal Program Studi $\begin{array}{lllll}P G M I & 8, & \text { no. } & 1 & \text { (2021) }\end{array}$ http://jurnal.stitnualhikmah.ac.id/index.p $\mathrm{hp} /$ modeling/article/view/717.

Ghofur, Abd. "USING GOOGLE CLASSROOM ON INQUIRY BASED LEARNING TO IMPROVE STUDENTS , LEARNING PARTICIPATION." Jurnal Penelitian Pendidikan 10, no. 2 (2018): 1503-1509. https://ejournal.stkippacitan.ac.id/index.p hp/jpp/article/view/226.

Kulsum, Siti, and Syifa Husnul. "Pemanfaatan Media Pembelajaran , Inovasi Di Masa Pandemi Covid-19." EDUKATIF : JURNAL ILMU PENDIDIKAN 3, no. 4 (2021): 21492158.

http://journal.stmikjayakarta.ac.id/index. php/jisamar/article/view/181.

Mendikbud RI. Surat Edaran Nomor 4 Tahun 2020 Tentang Pelaksanaan Kebijakan Pendidikan Dalam Masa Darurat Penyebaran Coronavirus Disease (COVID-19), 2020. https://www.kemdikbud.go.id/main/blog/ 2020/03/se-mendikbud-pelaksanaankebijakan-pendidikan-dalam-masadarurat-penyebaran-covid19.

Monica, Junita, and Dini Fitriawati. "Efektivitas Penggunaan Aplikasi Zoom Sebagai Media Pembelajaran Online Pada Mahasiswa Saat Pandemi Covid-19 As An Online Learning Medium For Students During The Covid-19 Pandemic." Jurnal Communio: Jurnal Jurusan Ilmu Komunikasi 9, no. 2 
Susilo, Adityo, C Martin Rumende, Ceva W Pitoyo, Widayat Djoko Santoso, Mira Yulianti, Robert Sinto, Gurmeet Singh, et al. "Coronavirus Disease 2019: Tinjauan Literatur Terkini." Jurnal Penyakit Dalam Indonesia 7, no. 1 (2020):

http://www.jurnalpenyakitdalam.ui.ac.id/ index.php/jpdi/article/view/415.

Thuaimah, Rusydi Ahmad; Naqah, Kamil Mahmud. Al Kitab Al Asasiy Li Ta'lim Al Lughah Al Arabiyyah Li an Nathiqina Bi Lughat Ukhra (I'daduhu Wa Tahliluhu Wa Taqwimuhu). Makkah: جامعة أم القرى, 1983.

Wargadinata, Wildana, Iffat Maimunah, and Suci Ramadhanti. "Mediated Arabic Language Learning for Arabic Students of Higher Education in COVID-19 Situation." Izdihar: Journal of Arabic Language Teaching, Linguistics, and Literature 3, no. 1 (2020): 1-20. http://ejournal.umm.ac.id/index.php/izdi har/article/view/11862.

Warsita, Bambang. Pendidikan Jarak Jauh: Perancangan, Pengembangan, Implementasi, Dan Evaluasi Diklat. Bandung: Remaja Rosdakarya, 2011.

Yuliana. "Corona Virus Diseases (Covid -19); Sebuah Tinjauan Literatur." WELLNESS AND HEALTHY MAGAZINE 2, no. 1 (2020): 187-192.

https://www.wellness.journalpress.id/wel lness/article/view/21026/pdf. 